\title{
Morphological, optical and thermal characterisation of aerogel- epoxy composites for enhanced thermal insulation
}

\author{
Suryanarayanan Krishnaswamy ${ }^{l}$, Debabrata Bhattacharyya ${ }^{2}$, Hrushikesh Abhyankarl ${ }^{1}$,Veronica Marchante ${ }^{l}$, \\ Zhaorong Huang ${ }^{2}$ and James Brighton ${ }^{1}$ \\ ${ }^{1}$ Advanced Vehicle Engineering Centre, Cranfield University, UK \\ ${ }^{2}$ Surface Engineering and Precision Institute, Cranfield University, UK
}

\begin{abstract}
The present work explores the possibility of introducing aerogel at different stages of the epoxy resin cure to identify the most effective method that ensures minimal destruction of the aerogel particles. The aerogel particles are added at 0.5 hours, 1 hour and 1.5 hours after the resin and the hardener are mixed together. Additionally, the effect of a wetting agent that improves the interface between the aerogel and the resin is also investigated. The different materials are characterised using optical images and ESEM-EDX to determine the most effective processing route. Additional data is also provided by determining the different material's optical transmittance and reflective characteristics. From the experimental results, it is observed that the addition of aerogel at the 1 hour mark proves to be the most efficient route to follow. In addition, the wetting agent displays a negligible effect on the samples in the study; hence its usage is advocated due to its influence on the interface strength. Therefore, the aerogel/epoxy/wetting agent sample with the aerogel added at the 1 hour mark looks promising. A $13.3 \%$ decrease in thermal conductivity when compared with the pure resin/hardener sample along with damage coefficient value of 0.183 demonstrates the material's potential for thermal insulation applications.
\end{abstract}

Keywords: Aerogel, Epoxy, Thermal Insulation, Damage coefficient, Composite materials

\section{Introduction}

Silica aerogels (hereby referred to as aerogels) are highly crosslinked and porous materials that consist of nanoporous matrices with amorphous silica particles that are interconnected (1)(2). These are prepared by replacing the liquid in a jelly by a gas with little/no shrinkage through a series of steps and allowing the latter to escape (3). This results in a material with, amongst others, low thermal conductivity $(0.012 \mathrm{~W} /(\mathrm{m} * \mathrm{~K}))$, density $\left(0.003-0.35 \mathrm{~g} / \mathrm{cm}^{3}\right)$, dielectric constant (1.1-2.2), thermal expansion coefficient $\left(2-4 * 10^{-6}\right)$ and refractive index (1-1.08) along with a high specific surface area $\left(500-1200 \mathrm{~m}^{2} / \mathrm{g}\right)$ and porosity $(>90 \%)$ $(4)(5)(6)(7)$. These properties of the aerogel have led to its use in various industrial applications such as thermal insulation for transport vehicles, pipes, cryogenics, portable coolers, space vehicles, casting moulds and building applications (8)(9)(10). However, widespread use of silica aerogels has been limited because of their fragility, demand for supercritical drying and hydrophilicity (11)(12). Therefore to overcome the fragility, combination of the aerogel with a polymer thereby taking advantage of the mechanical strength of the latter with the thermal stability of the aerogel is suggested (11)(12). One such method is proposed by Schmidt \& Schwertfeger (13) wherein, the use of polymers as a binding material (matrix) is considered. This study investigates the application of a wet and a dry binding system in which, the liquid system (aqueous vinylacetate/ethene) using dispersion showed a better coefficient of thermal resistance over a dry thermoplastic (PVB) system. In work, Kim and Hyun (6) compared the thermal conductivity of aerogel mixed differently with a similar material; PVB powders (dry mixing) and PVB-toluene solution (wet mixing) and showed the former had a lower value of thermal conductivity compared to the later. However, the authors also noted that dry mixing results in a less homogenous mixture and could not retain the original composite shape for aerogel volume percentages over 70 . 
Therefore, a liquid epoxy resin system is chosen as the binding material in the current study because of the material's widespread usage in composite materials, adhesives and moulding compounds $(14)(15)(16)$.

Basri et al. (17) obtained good water absorption test results for silica aerogel/epoxy nanocomposites by reducing the stirring speed and increasing the stirring time when mixing the aerogel with the pure resin and, by increasing the stirring speed and shortening the time when mixing the previous mixture with a hardener. According to Zhao et al. (18), aerogel/epoxy composites have thermal conductivities as low as $0.105-0.175 \mathrm{~W} /(\mathrm{m} * \mathrm{~K})$ and the relationship between the property and the weight fraction of the aerogel is not linear. Additionally, their study also showed that bigger aerogel particles $(0.2-2 \mathrm{~mm})$ provided better thermal properties than smaller particles $(<0.2 \mathrm{~mm})$. In another work, Gupta and Ricci (19) demonstrated better mixing of the aerogel particles by reducing the viscosity of the resin using higher temperatures. Nevertheless the authors of both research ((18) and (19)) comment on the possible infiltration of the resin into the pores of the aerogel. This effect was further noted in the work by Vahtrus et al. (20) wherein the authors observed an increase in the thermal conductivity of aerogel/epoxy composites due to the filling of the resin into the pores of the aerogel. Kim et al (21), however, demonstrated lower thermal conductivity values for samples manufactured using ethanol evaporation to preserve the pores; these samples showed better thermal performance when compared to as-received and plasma treated aerogels across different volume fractions.

The present study however, looks to limit the resin infiltration by increasing the viscosity of the curing resin before the aerogel addition. This is done to simplify the production process without the need for auxiliary solvents like ethanol which are highly flammable and potentially explosive(22) (23). To negate the loss in the wetting due to a more viscous resin (as discussed in (19)), the effect of a wetting agent is also investigated. The aerogel particles are stirred into the resin system at different time intervals after the addition of the hardener and the morphology of the sample is determined. The samples are characterised using optical images and energy dispersive spectra data from an environmental scanning electron microscope (EDX-ESEM). The optical spectral property is determined using a spectrophotometer which measures the transmittance and reflectance characteristics of the materials. Finally, the thermal conductivity of the material processed through the most promising route is evaluated and a damage coefficient value is calculated to enable quantification of the aerogel destruction within the same.

\section{Methodology}

\subsection{Materials}

To process the materials in the present study, RS-M135 (PRF composites, UK) epoxy resin along with a custom hardener blend of RS-MH137 and RS-MH134 (both supplied by PRF composites) in a 2:1 weight ratio were chosen for the preparation of the matrix (binder). The resin to hardener weight ratio used was 10:3. The samples for morphological and spectrophotometry analysis were made by mixing the resin and the hardener using the given ratios and then degassing the mixture using vacuum at room temperature for 10 mins. The contents were then removed and stored in closed containers. When the sample was ready for analysis, 0.03 mass fraction of Enova Aerogel IC3110 (supplied by Cabot Corporation, USA) 
was added into the resin and manually stirred before being placed inside the apparatus. The times of addition and hence, the analysis were $0.5,1$ and 1.5 hours after the hardener was mixed in. Hence, each batch was further divided into 3 samples depending on the time of aerogel addition- $0.5,1,1.5$ (reflecting the time of addition).

Batch A was used as a control and was made using only the resin and the hardener. Batch B was a composite of the resin, hardener and the aerogel particles. Batch $\mathrm{C}$ was similar to batch B with the exception of a wetting agent (BYK-P 9920, BYK-Chemie, Germany) which was added into the resin before the hardener. As recommended by the supplier, 3\% (of the total weight of the solution) of wetting agent was added and stirred in. Therefore, the present study had a total of 9 samples; three in batch $\mathrm{A}(0.5 \mathrm{~A}, 1 \mathrm{~A}$ and $1.5 \mathrm{~A})$, three in batch $\mathrm{B}(0.5 \mathrm{~B}, 1 \mathrm{~B}$ and $1.5 \mathrm{~B})$ and three in batch $\mathrm{C}(0.5 \mathrm{C}, 1 \mathrm{C}$ and $1.5 \mathrm{C})$.

For spectrophotometry and morphological analysis, a solution containing $10 \mathrm{~g}$ of deionised water and $0.05 \mathrm{~g}$ of methylene blue powder (C.I. 52015) supplied by Merck (Germany) was mixed and 2-3 drops of the solution was added into each of the spectrophotometry (and microscope) samples during its processing to colour it. Once the materials were prepared, they were then manually spread onto a glass slide prior to the analysis. After the spectrophotometry test runs, the samples in the glass slide were left to fully cure (minimum of 5 days) at room temperature before being observed under the microscopes.

For the samples used for thermal conductivity testing, the resin was left inside the vacuum oven for the whole duration i.e., 1 hour, before the addition of aerogel. After which, they were transferred to a glass mould and allowed to cure. The pure resin sample was cured at $60^{\circ} \mathrm{C}$ for 24 hours and the composite sample- $1 \mathrm{C}$ was cured at room temperature for 48 hours. Once cured, sample sizes of $30 \times 30 \times 4 \mathrm{~mm}$ were cut from all the batches and tested. The aerogel-epoxy sample was cured at room temperature because a higher cure temperature would decrease the viscosity of the resin and hence, increase its rate of infiltration into the aerogel.

\subsection{Surface Morphology}

Batches B and C which contain the aerogel were studied under a Nikon Optiphot image acquisition system equipped with a Leica Application suit. All the samples were imaged under a $5 \mathrm{X}$ magnification. The samples were left to cure at room temperature after spectrophotometer analysis before viewing them under the microscope.

The same samples were also studied using a Phillips XL30ESEM environmental scanning electron microscope (ESEM) equipped with an energy dispersive spectra (EDX) for compositional analysis.

\subsection{Optical Spectrophotometry}

The optical transmission performance of the test samples was characterised using an UVvisible-NIR spectrophotometer, Jasco V-670 at normal incidence wherein the surrounding air medium in the sample chamber was used as reference for spectral calibration. The 3 batches of samples were measured in the wavelength range of $300 \mathrm{~nm}$ to $1500 \mathrm{~nm}$ at a scan speed of $400 \mathrm{~nm} / \mathrm{min}$. Each batch had three different test samples into which the aerogel was added at 0.5 hours, 1 hour and 1.5 hours (for batches B and C) respectively. With respect to batch Athe pure resin; the samples were measured without any mixing of the aerogel and the wetting agent after required time period- this batch was used as a control. It should be noted that the 
curing of the resin on the glass slide was carried out during the measurement period itself. As shown in Figure 1, the glass substrate was placed vertically in the sample chamber of the spectrophotometer. Six consecutive scans at 5 minute intervals for each test sample were undertaken to evaluate the transmittance characteristics of the curing sample. The film thickness and uniformity would not remain same for the 6 runs during the process due to the resin flow and the sample's change of phase from liquid to solid which may introduce an uncertainty in comparing the transmittance spectra (e.g. change in intensity) of various test samples. However, the measurement error is expected to be minimum since the film is quite thick (few $\mathrm{mm}$ ) in nature.

In addition, total reflectance of the spectra in the range of 200-1500 nm, e.g., both diffuse and specular, was measured using an integrating sphere of $60 \mathrm{~mm}$ diameter and fluro-polymer based spectralon as a calibration standard. This gives the nature of light scattering due to the presence of aerogel and/or other particulates in the samples. It is also believed that the reflectance spectra would allow the possibility of detecting the nano-pores that could have been retained during the processing of batches $\mathrm{B}$ and $\mathrm{C}$.

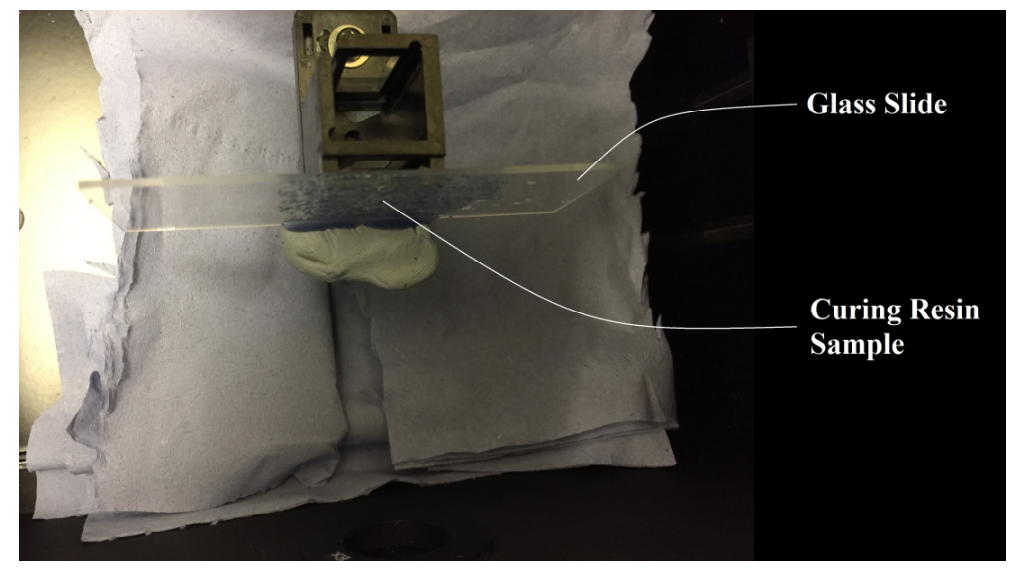

Figure 1 Test sample placed in the chamber of the spectrophotometer during curing process

\subsection{Thermal Conductivity}

The thermal conductivity of the samples was measured using the TCi Thermal conductivity analyser (C-Therm, Cannada). As the samples were stiff, distilled water was used as a contact agent wherein, three drops were added onto the sensor before the samples were placed in position. For each sample, 10 measurements were undertaken and the average value is used to determine the thermal conductivity of the sample.

\section{Experimental Results}

\subsection{Optical Microscope}

\subsubsection{Batch B}

The optical image of batch $0.5 \mathrm{~B}$ (in Figure 2) shows particles that are around $500 \mu \mathrm{m}$ in size and almost spherical in nature. These are believed to be the aerogel particles in the resin since the aerogel powder used in the present study are between 100-700 $\mu \mathrm{m}$ in size (24). However, owing to the resin surrounding the particles, the ability to see within the structure and to predict the amount of infiltration is not possible with the current method. However, the results do show the distribution of coalesced silica/aerogel particles which could potentially 
signify the presence of aerogel with limited infiltration. Additionally, Figure $2 \mathrm{c}$ shows smaller circular features which are thought to be the air pores formed during the processing of the composite material.

When comparing the results of the different batches, it was observed that similar aerogel-like structures were also found in batches $1 \mathrm{~B}$ and 1.5B as shown in Figure 3 and Figure 4 respectively indicating the possible existence of aerogel particles in all samples. However, when considering sample 1.5B the existence of pronounced darker and lighter areas were seen (Figure 4c) which could be due to the lower flow rate of the resin which is more cured at this stage. High viscosity is expected to adversely affect the final composite material because of loss in mouldability and the application of more force needed to mix that could destroy the fragile aerogel. This destruction is potentially seen in Figure $4 \mathrm{~b}$ where the aerogel structures do not have smooth and clear boundaries. Although sample 1B also shows similar breakage of the aerogel, the boundaries are better defined compared to sample 1.5B as seen in Figure $3 \mathrm{a}$ and $\mathrm{c}$.

Therefore, while sample $0.5 \mathrm{~B}$ showed a much better retention of the overall structure of the aerogel, the lower viscosity of the resin during the aerogel addition could potentially result in a higher infiltration of the former into the latter. On the other hand, sample 1.5B showed much higher viscosity which would result in a greater difficulty whilst moulding complex shapes and could break the aerogel during the mixing process. Hence, the addition of the aerogel at around the 1 hour mark is recommended; wherein sample 1B shows limited breakage as compared to sample $1.5 \mathrm{~B}$ and the higher viscosity would result in a lower infiltration of the resin compared to sample $0.5 \mathrm{~B}$.

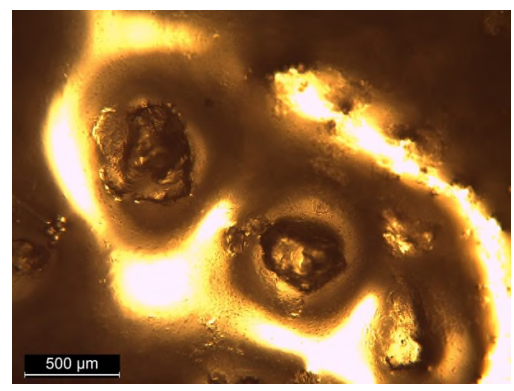

a

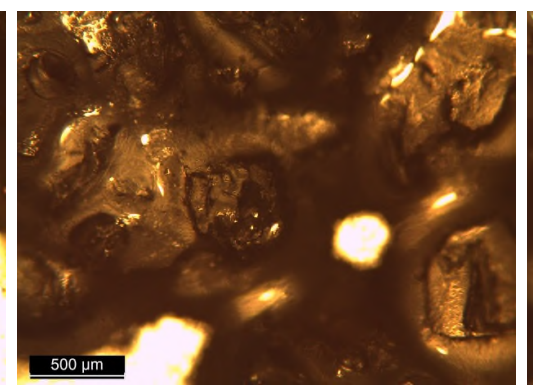

b

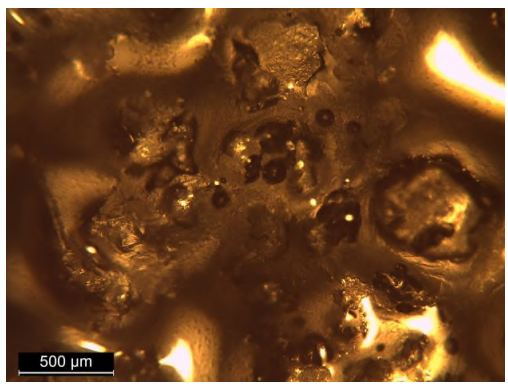

$\mathrm{c}$

Figure 2 Optical images of Batch 0.5B

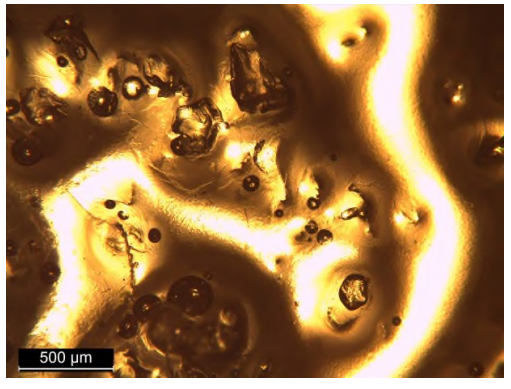

a

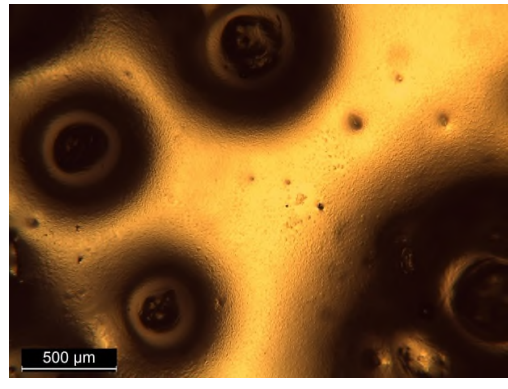

b

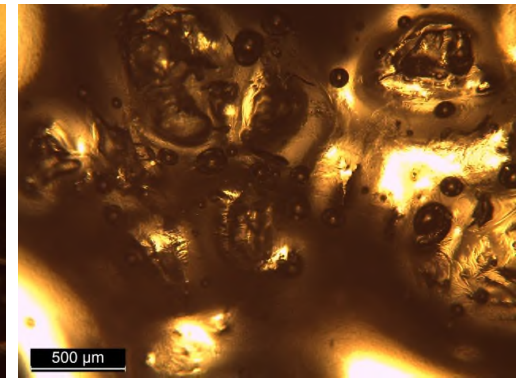

c

Figure 3 Optical images of Batch 1B 


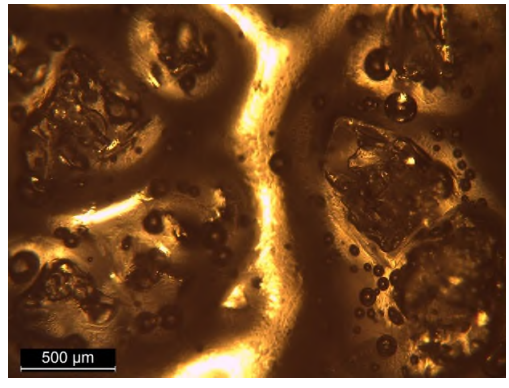

a

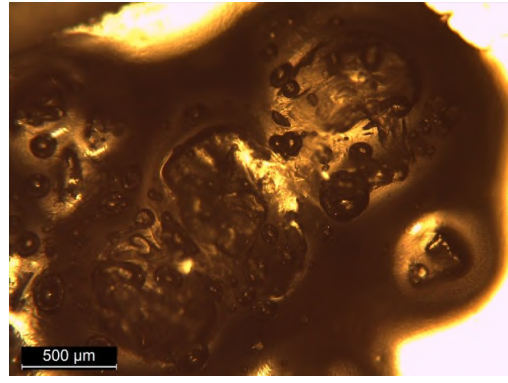

b

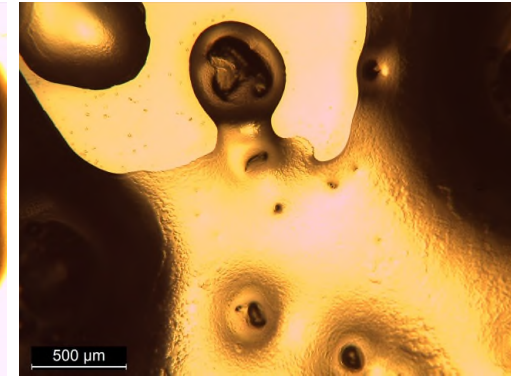

c

Figure 4 Optical images of Batch 1.5B

\subsubsection{Batch C}

Microscopic images obtained for batch $\mathrm{C}$ are shown in Figure 5, Figure 6 and Figure 7 for $0.5 \mathrm{C}, 1 \mathrm{C}$ and $1.5 \mathrm{C}$ respectively. Similar to batch $\mathrm{B}$, sample $0.5 \mathrm{C}$ shows a more holistic aerogel structure compared to sample $1.5 \mathrm{C}$ whose destruction can be seen especially in Figure $7 \mathrm{~b}$. But the lower viscosity of the resin in the $0.5 \mathrm{C}$ sample would result in a higher rate of infiltration. Therefore, it is once again suggested that the aerogel-epoxy composites must balance the ability to mould complex shapes and potentially, the mechanical destruction of the aerogel with the infiltration of the resin. Hence, the addition of the former must be inbetween the two extremes at around the 1 hour mark since the images for sample 1C (Figure 6) do not show similar levels of destruction as compared to sample $1.5 \mathrm{C}$ and the higher viscosity of the curing resin at this stage when compared to sample $0.5 \mathrm{C}$ would ensure a lower level of resin infiltration.

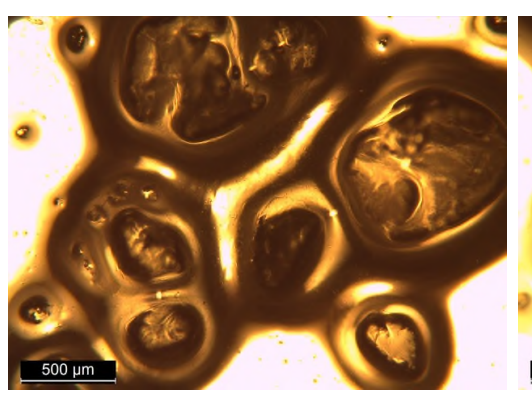

a

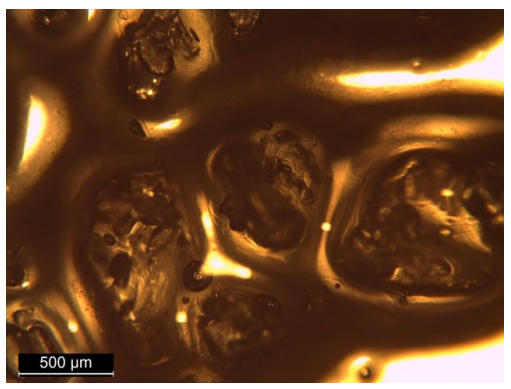

a

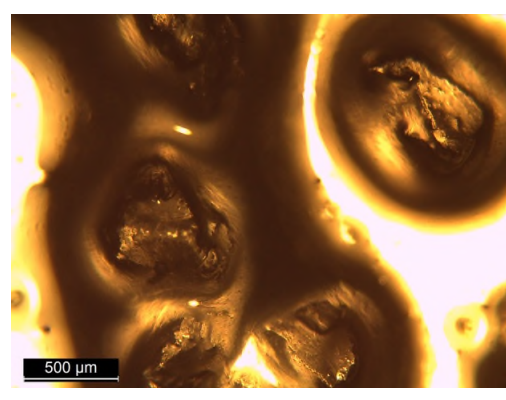

b

Figure 5 Optical images of Batch 0.5C

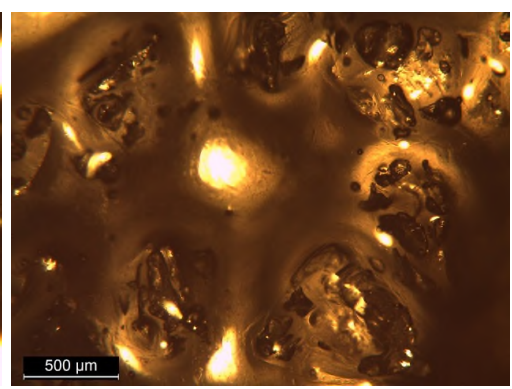

b

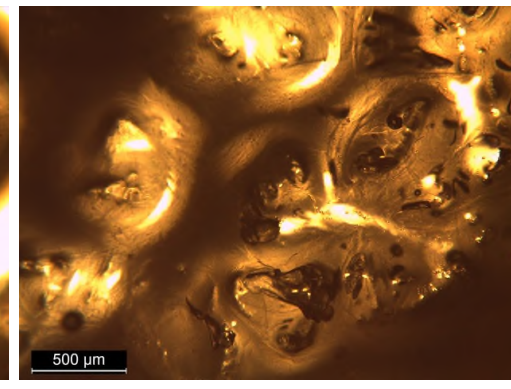

$\mathrm{c}$

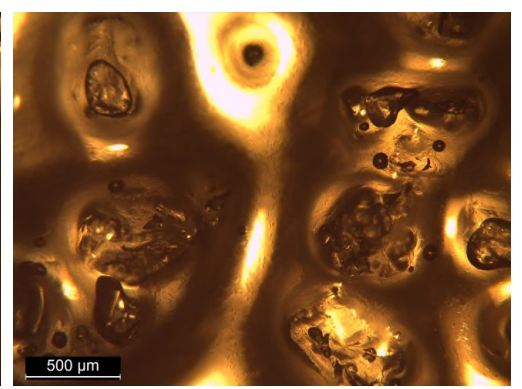

C

Figure 6 Optical images of Batch 1C 


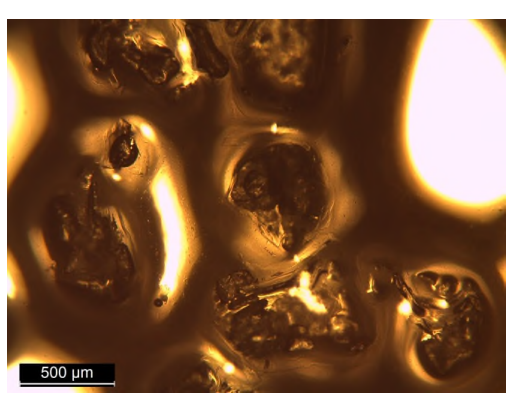

a

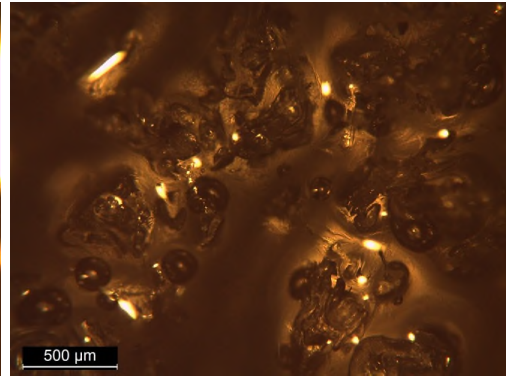

b

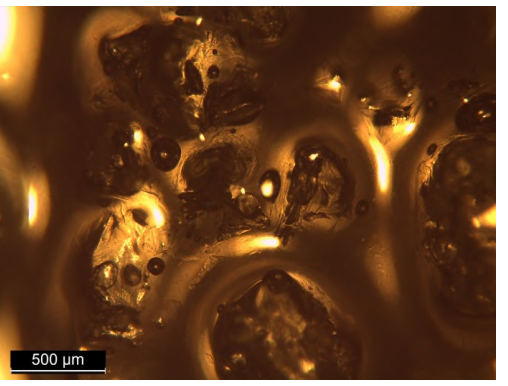

c

Figure 7 Optical images of Batch 1.5C

\subsection{Scanning Electron Microscope}

\subsubsection{Batch B}

EDX linescans showing the elemental composition across a line drawn through an ESEM image for batch B are illustrated in Figure 8. It must be noted that only the information (EDX) for carbon (C) and silicon (Si) are shown and compared for convenience of analysis.

Figure 8a shows the linescan across an aerogel particle in sample 0.5B. The EDX analysis indicates the presence of silica in the particle thereby confirming the existence of aerogel. The graph pertaining to carbon (C) shows its presence in the particle as well suggesting the infiltration of resin into the aerogel. Figure 9 also shows that the aerogel particles (spectrum 7 and 8 ) have a higher weight percentage of Si compared to the matrix (spectrum 9). However, all three spectrums show high levels of $\mathrm{C}$ providing further evidence for resin infiltration into the aerogel particles. Figure 9 also shows regions of high Si content (spectrum 6 and 10) which are lighter in colour compared to the surrounding areas. These areas are believed to be regions of low resin content as reflected by the weigh percentage of $\mathrm{C}$. The spectrums here could be that of the glass slide since these regions also show a higher presence of sodium $(\mathrm{Na})$, magnesium $(\mathrm{Mg})$, potassium $(\mathrm{K})$ and calcium $(\mathrm{Ca})$. One explanation for this could be due to the sample being held vertically for the spectrophotometer data wherein, the downward movement of the resin could have left certain areas with lower amounts of the material and hence, the EDX would have detected the composition of the glass substrate instead. A similar area is also shown on the right side of Figure $8 \mathrm{a}(\sim 1600 \mu \mathrm{m})$ with higher Si content.

Figure $8 \mathrm{~b}$ shows the linescan of an aerogel particle in sample 1B. The distribution of silicon (Si) is similar to the scan of sample $0.5 \mathrm{~B}$ (Figure $8 \mathrm{a}$ ). Whilst analysing the distribution of carbon $(\mathrm{C})$, it was observed that there is a decrease in its content (circled in the image) through the particle for sample 1B; however, this 'well-type' distribution is not clearly visible in sample $0.5 \mathrm{~B}$ thereby suggesting a lower level of resin infusion for sample 1B.

Additionally, a spectrum map of sample 1B is also shown in Figure 10 which depicts increased levels of $\mathrm{Si}$ accompanied by lower levels of $\mathrm{C}$ for the aerogel particles.

The linescan for sample 1.5B is presented in Figure $8 \mathrm{c}$ wherein coalesced particles are observed. As evidence from the image, these particles contain Si thereby providing evidence to the claim that these are broken aerogel/silica particles. These are thought to be due to the mechanical destruction of the aerogel during mixing (as discussed in the previous section) because of the particles' smaller size when compared to an undamaged aerogel particle. 

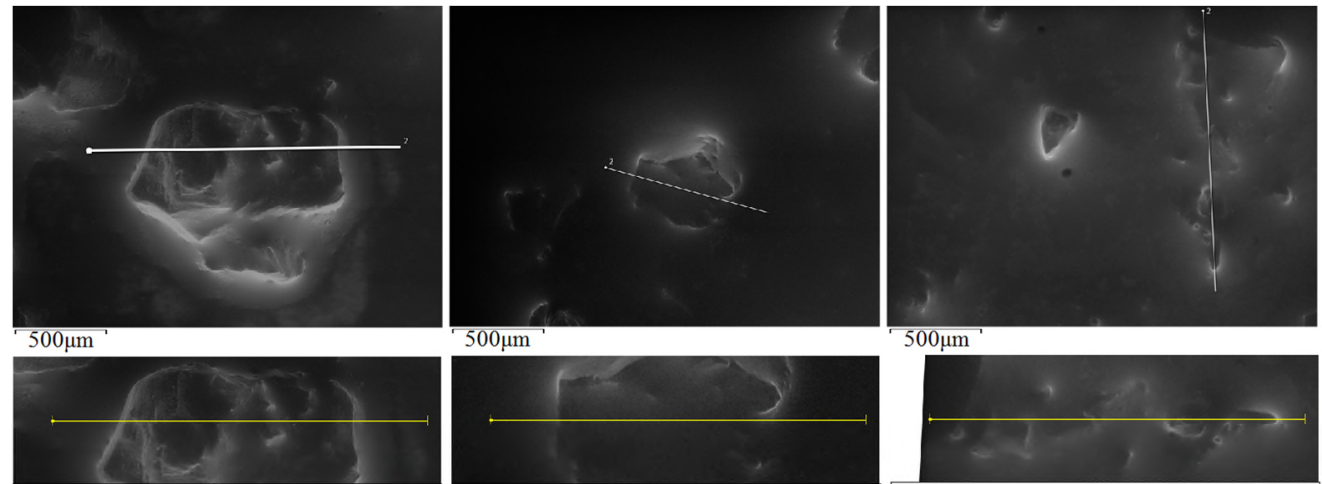

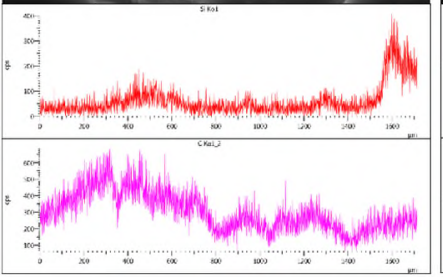

Sample $0.5 \mathrm{~B}$

(a)

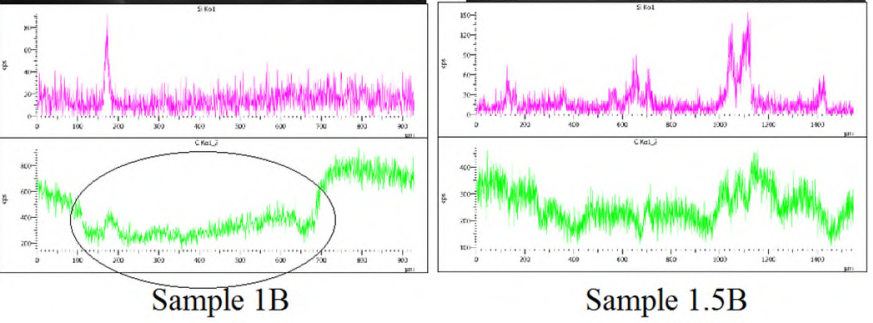

(b)

(c)

Figure 8 Line scans of samples in batch B with the well-like distribution of sample 1B circled in the graph; the top spectrum represents silicon $(\mathrm{Si})$ and the bottom spectrum represents carbon $(\mathrm{C})$
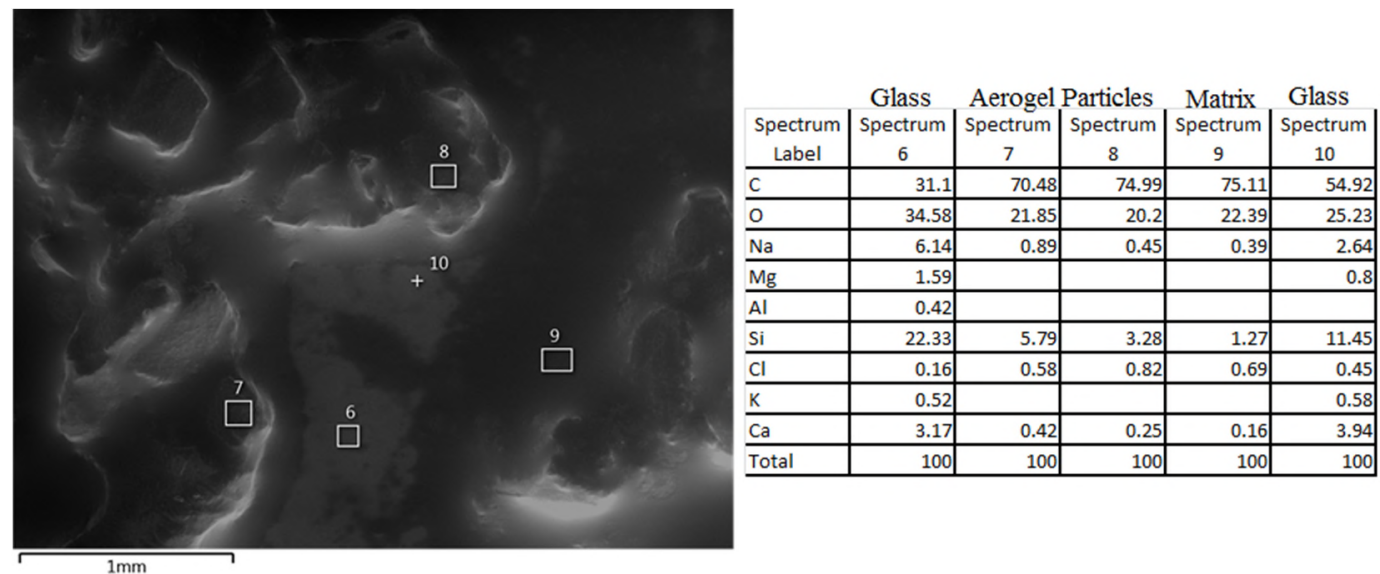

Figure 9 EDX analysis of Sample 0.5B (the elemental composition in the spectra are given in terms of weight percent) 

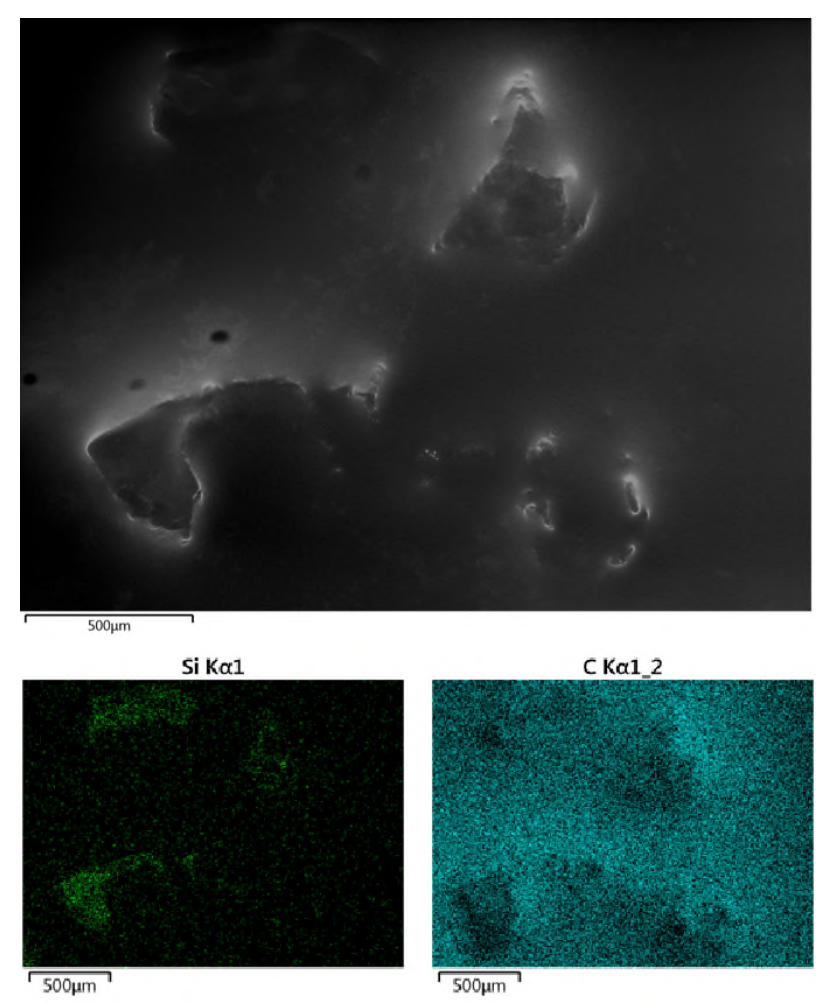

Figure 10 Spectrum map of sample 1B

\subsubsection{Batch C}

Figure 11a shows the EDX linescan of an aerogel particle in sample $0.5 \mathrm{C}$ wherein, silicon (representing silica) is detected. However, similar to sample $0.5 \mathrm{~B}$, the scan representing carbon shows small variances across the scanned area, suggesting an infiltration of the resin into the aerogel. This is further proven through Figure 12 in which spectrums 1, 4 and 5 within the particle not only show the presence $\mathrm{Si}$, but the percentage of $\mathrm{C}$ does not decrease when compared to the matrix (spectrums 2 and 3).

When considering the EDX results of sample 1B (Figure 11b) it is observed that the linescan across an aerogel particle shows a decrease in carbon (C) along with an increase in silicon (Si). Once again, a well-like distribution of carbon (circled in the figure) is observed across the aerogel particle. This suggests the presence of silica aerogel particles with decreased resin infiltration as compared to sample 0.5C. To further illustrate, an EDX spectrum map of sample 1C is presented in Figure 13. It is seen that, similar to Figure 10 for sample 1B, the position of the aerogel particles is represented by lower carbon and higher silicon content compared to the neighbouring matrix.

Finally, the results of sample $1.5 \mathrm{C}$ also show a decrease in the level of carbon (C) within the aerogel particle (Figure 11c) similar to sample 1C with a well-like distribution. However, as illustrated in Figure 14, the particles in the sample show signs of mechanical destruction i.e., the aerogel has not been able to retain its spherical structure perhaps due to the increased viscosity of the resin. 


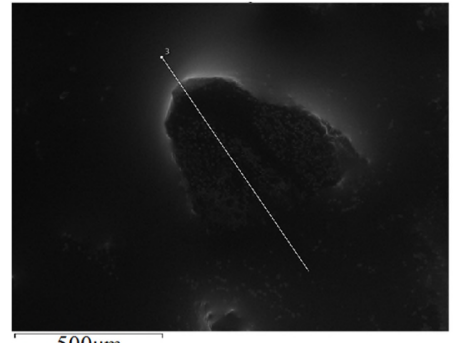

$500 u \mathrm{~m}$
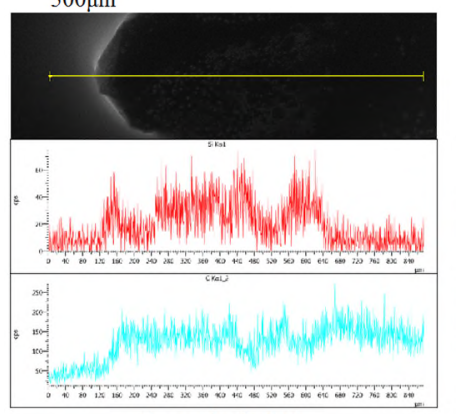

Sample $0.5 \mathrm{C}$

(a)

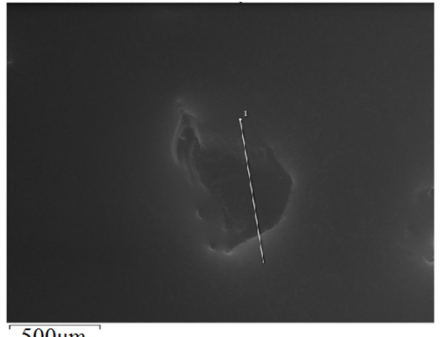

$500 \mu \mathrm{m}$
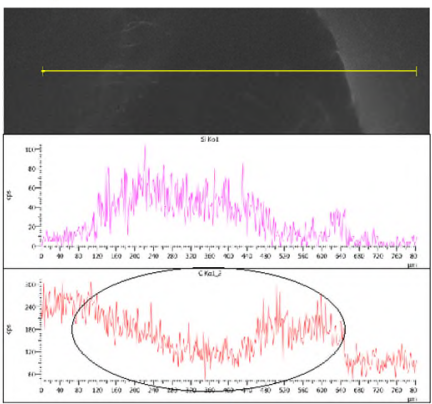

Sample 1C

(b)

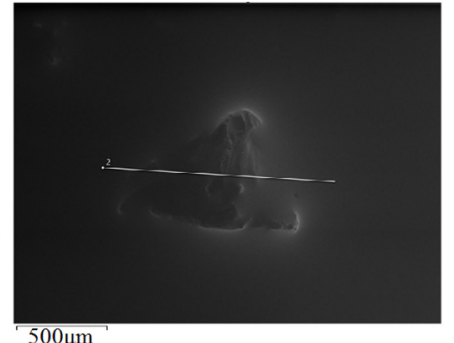

$500 \mu \mathrm{m}$

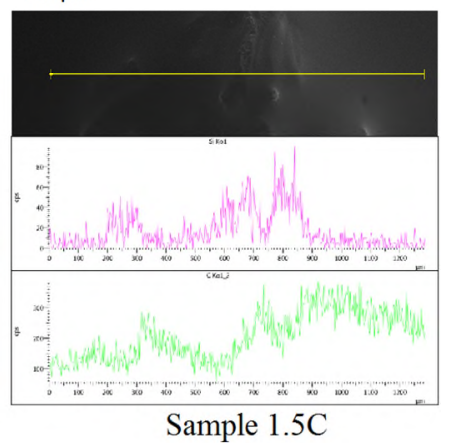

(c)

Figure 11 Line scans of samples in batch $\mathrm{C}$ with the well-like distribution of sample $1 \mathrm{C}$ circled in the graph; the top spectrum represents silicon $(\mathrm{Si})$ and the bottom spectrum represents carbon $(\mathrm{C})$

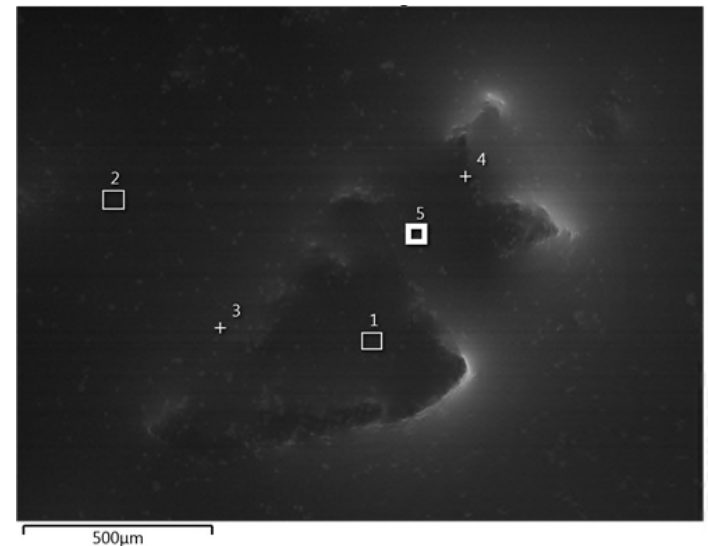

\begin{tabular}{|c|c|c|c|c|c|}
\hline Spectrum & | spectrum | & Spectrum | & | Spectrum | & Spectrum & | Spectrum | \\
\hline Label & 1 & 2 & \begin{tabular}{|l|} 
\\
\end{tabular} & & \\
\hline $\mathrm{c}$ & \begin{tabular}{|c|}
79.37 \\
\end{tabular} & 79.69 & 80.76 & 80.68 & 80 \\
\hline 0 & \begin{tabular}{|c|}
19.03 \\
\end{tabular} & 18.99 & 17.11 & 17.11 & 18.56 \\
\hline Si & 0.24 & & & 1.01 & 0.26 \\
\hline $\mathrm{Cl}$ & 1.36 & 1.32 & 2.13 & 1.19 & 1.18 \\
\hline Total & 100 & 100 & 100 & 100 & 100 \\
\hline
\end{tabular}

Figure 12 EDX analysis of Sample $0.5 \mathrm{C}$ (the elemental composition in the spectra are given in terms of weight percent) 

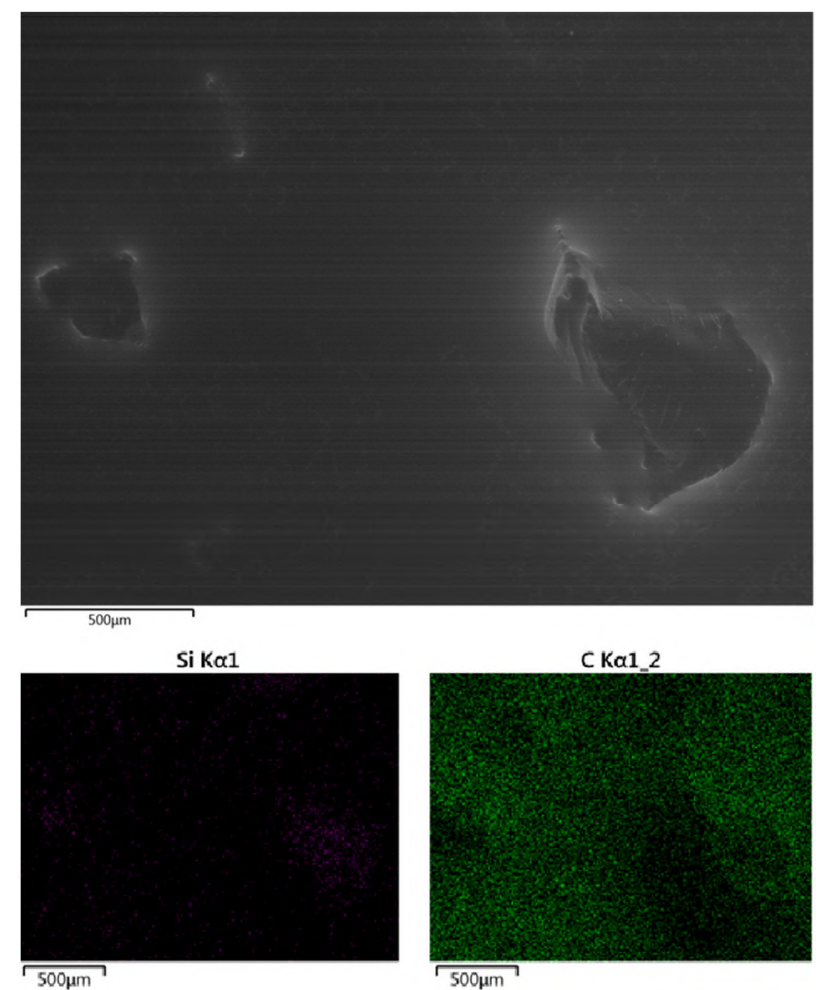

Figure 13 Spectrum map of sample 1C
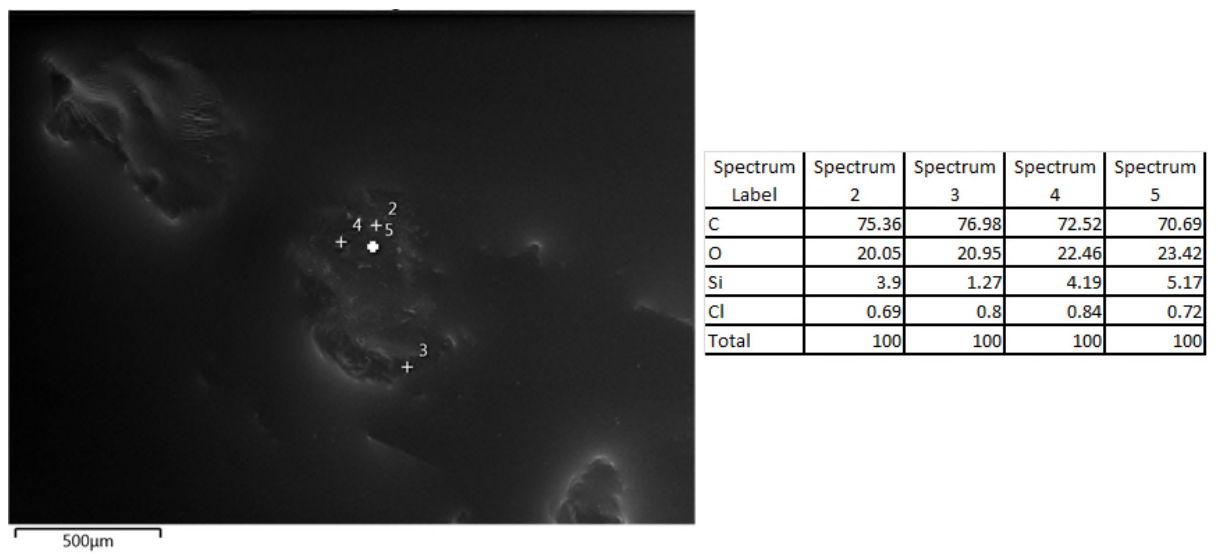

Figure 14 EDX analysis of Sample 1.5C (the elemental composition in the spectra are given in terms of weight percent)

\subsection{Optical transmittance and scattering characteristics}

The transmittance characteristics of the three batches are discussed in the current section. As described previously, each of the three batches is further divided into 3 samples depending on the time of aerogel addition i.e., 0.5 hours, 1 hour and 1.5 hours. Additionally, each sample was subjected to 6 measurement runs in the spectrophotometer at 5 minute intervals with run 1 starting at 0 minutes and run 6 starting at 25 minutes after the sample was placed inside the apparatus. The results for the aerogel-epoxy samples (batches B and C) at the 1 and the 1.5 hour mark are shown in Figure 15 and Figure 16 respectively. It was observed that the transmittance value for sample $1 \mathrm{~A}$ increased from $79.6 \%$ to $85.8 \%$ at $665 \mathrm{~nm}$ from run 1 to run 6 . However, the transmittance for the aerogel-epoxy composites had decreased for the samples $1 \mathrm{~B}$ and $1 \mathrm{C}$ showing a change in value from $25.9 \%$ (run 1 ) to $16.6 \%$ (run 6 ) and $28.3 \%$ (run 1 ) to $21.1 \%$ (run 6 ) respectively at $665 \mathrm{~nm}$. The 1.5 hour aerogel samples show 
similar trends to the 1 hour samples, wherein sample 1.5A exhibits an increase in the transmittance values from $73.3 \%$ at run 1 to $80.7 \%$ at run 6 . However, the values for the composite samples remained relatively constant with a minimal drop from $10.4 \%$ (run 1 ) to $9.9 \%$ (run 6 ) in sample $1.5 \mathrm{~B}$ and $37.2 \%$ (run 1 ) to $35.8 \%$ (run 6) in sample $1.5 \mathrm{C}$. Figure 15 also shows a part of the graph generated by sample $1 \mathrm{C}$ between $665 \mathrm{~nm}$ and $1200 \mathrm{~nm}$ that is zoomed in for a clear demarcation between the runs. Although, the transmittance is only derived at a single wavelength at $665 \mathrm{~nm}$, the difference between the initial and final run over the whole range is illustrated in Figure 17 for comparison for batch $\mathrm{C}$ i.e., samples $1 \mathrm{C}$ and $1.5 \mathrm{C}$.

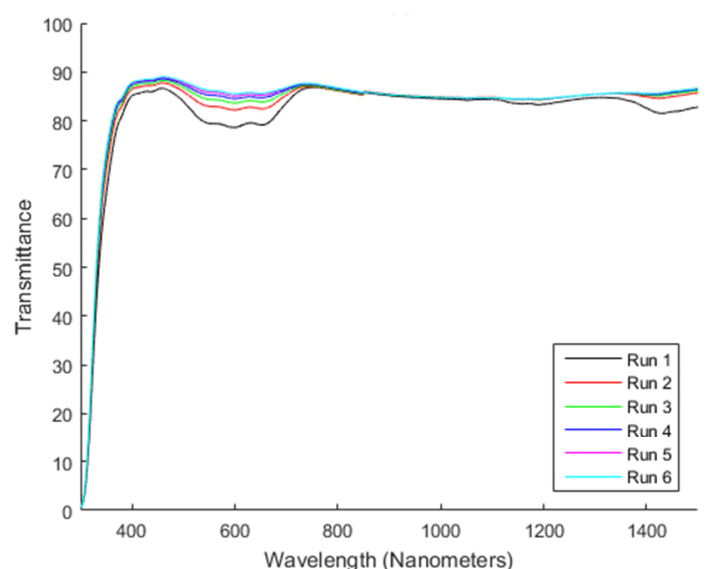

$\underline{\text { Batch A }}$

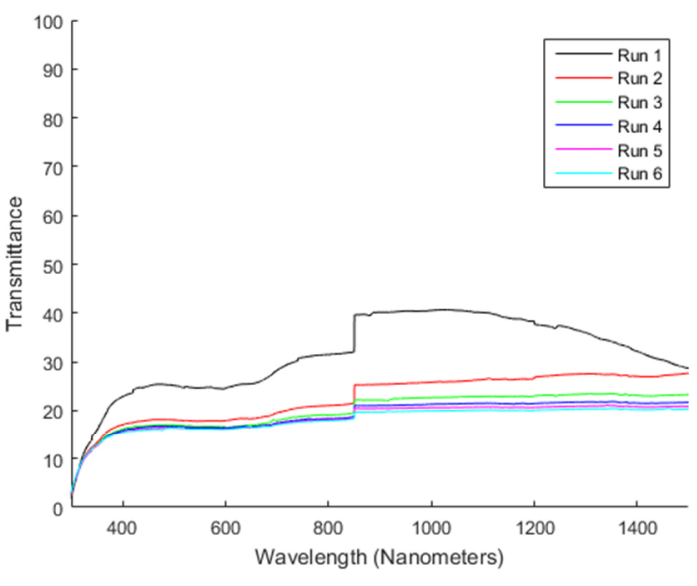

Batch B

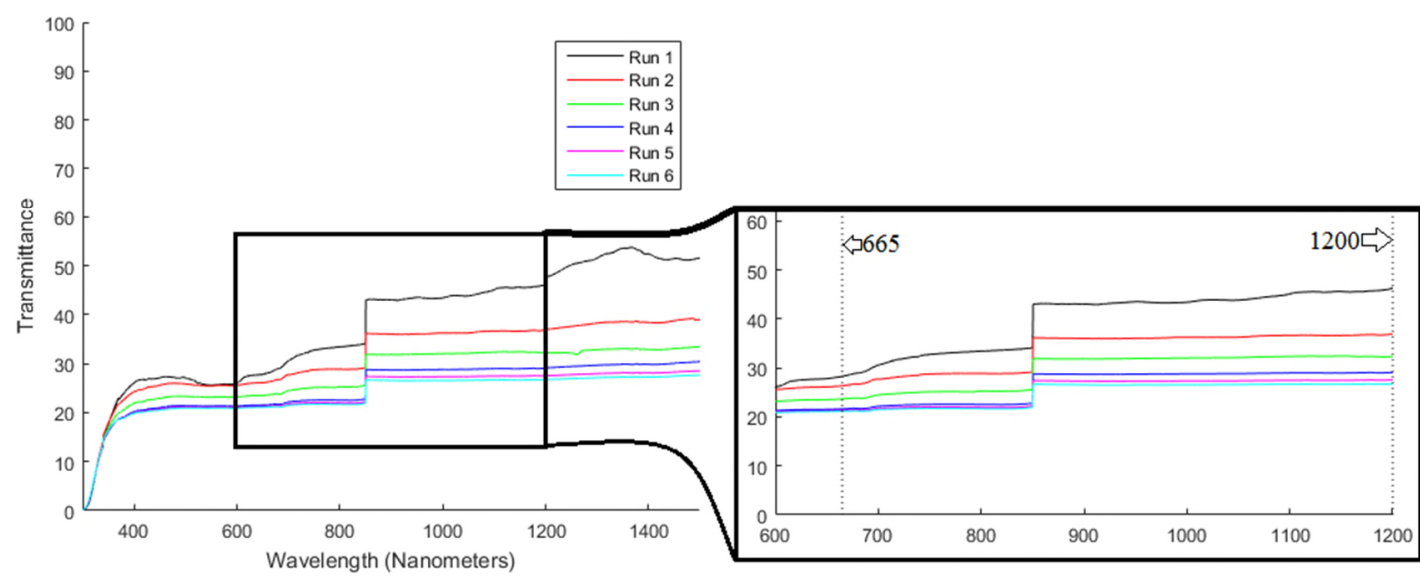

Batch C

Figure 15 Transmittance of test samples, A, B and C at 1 hour. For sample 1C, a section is highlighted for comparison of various test run. 


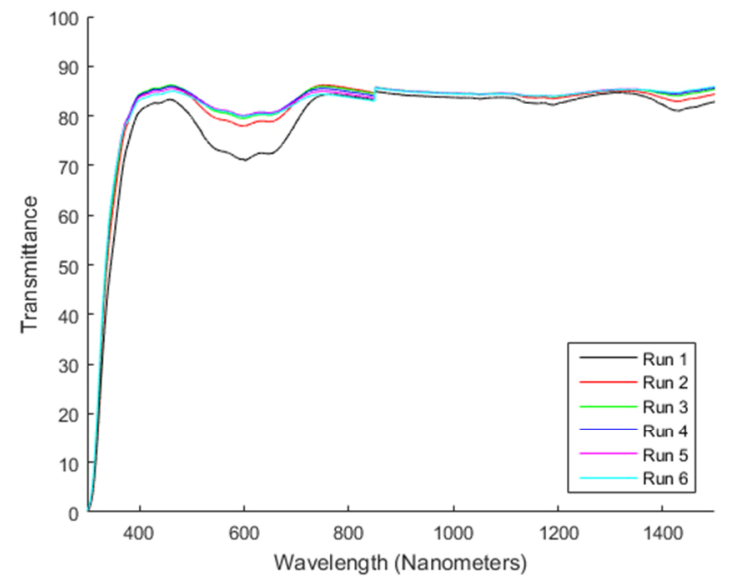

Batch A

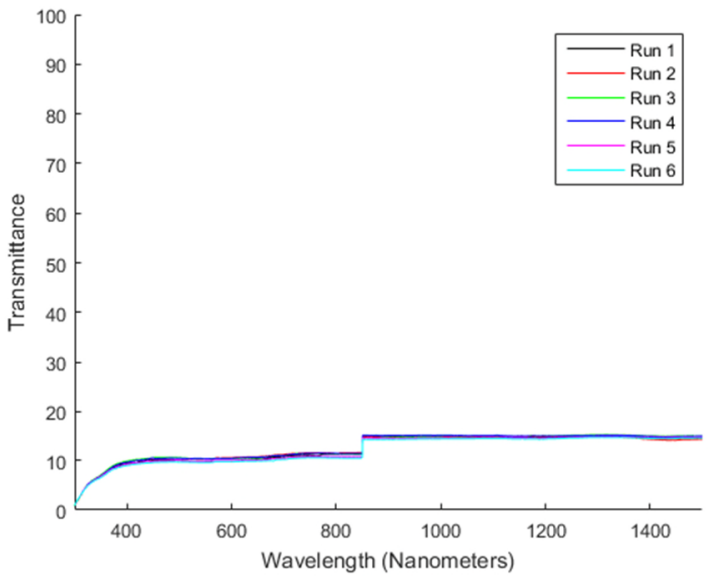

Batch B

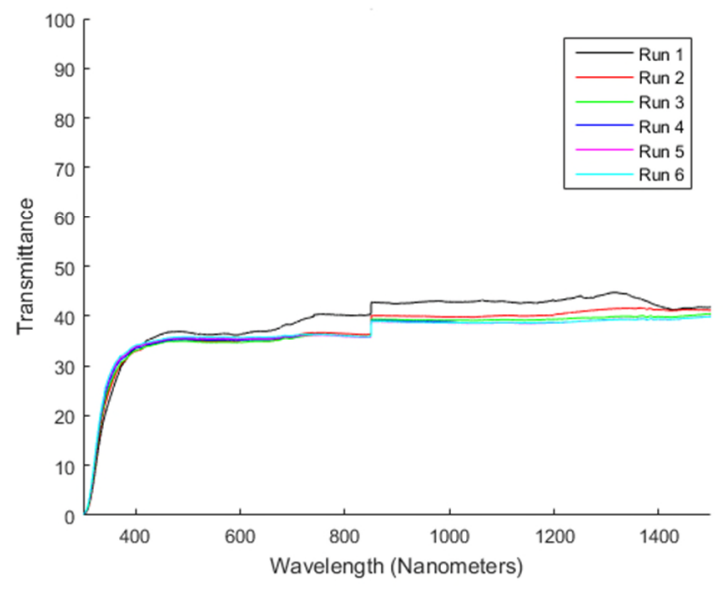

$\underline{\text { Batch C }}$

Figure 16 Transmittance of test samples, A, B and C at 1.5 hours

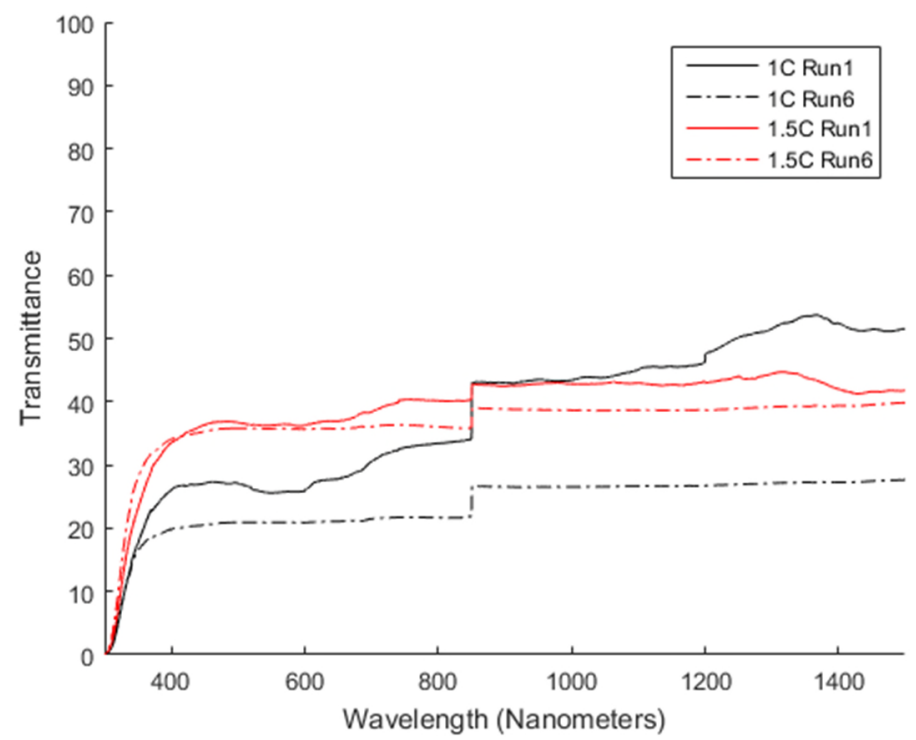

Figure 17 Comparison of the spectrophotometer results for samples $1 \mathrm{C}$ and 1.5C. For clarity only the initial (Run 1) and final (Run 6) runs are shown

Additionally, there was a sharp decrease in the transmission between the epoxy resin and the aerogel-epoxy composite, so the total reflectance of the three batches was measured using an integrating sphere. Samples $1 \mathrm{~B}$ and $1 \mathrm{C}$ were chosen since they are the most promising 
candidates to retain the aerogel structure and enable the production of complex shapes. The transparent resin-hardener sample whose refractive index of $\sim 1.5$ (25) is expected to exhibit a similar nature of diffuse reflectance obtained from a glass slide having an index of 1.52. Here, the glass slide (typically, $8 \%$ reflectance) and S-1A are used as reference to study the nature of scattering. Figure 18 shows that all 4 samples have similar reflectance performance in the range of $400 \mathrm{~nm}$ to $1500 \mathrm{~nm}$. The results demonstrate that all samples had negligible differences in scattering from the surface. However, the nature of scattering below $350 \mathrm{~nm}$ is different for each sample with an increase from $8 \%$ to close to $20 \%$ for all samples with the exception of the glass slide. As shown in Table 1, the absorption value (calculated by subtracting the value of transmittance and reflectance with 100) of sample $1 \mathrm{~A}$ is low; $6.4 \%$ at $665 \mathrm{~nm}$ and is mostly transparent over visible and NIR bands. The absorption in samples B and $\mathrm{C}$ are $75.4 \%$ and $70.9 \%$ respectively at $665 \mathrm{~nm}$ which are very high due to the particulate nature of aerogel and film thickness. The lower value of transmittance in samples B and $\mathrm{C}$ could be attributed to the opaque nature of the final solution following chemical mixing and curing since the aerogel has a complex nature of refractive index; the real part of the index is 1.02 (26) which is close to air, but it is believed that the imaginary index e.g., absorption coefficient plays a dominant role in the spectral performance thereby resulting in a lower transmittance (27). It must be noted that although the transmission readings were taken during the cure of the resin (run 6), it is believed that the transmission characteristics of the epoxy resin after cure should not change appreciably as reported (28). Hence, the spectral transmission of sample A remains the same as shown in Figure 15 and therefore, it was used for comparative study in Table 1.

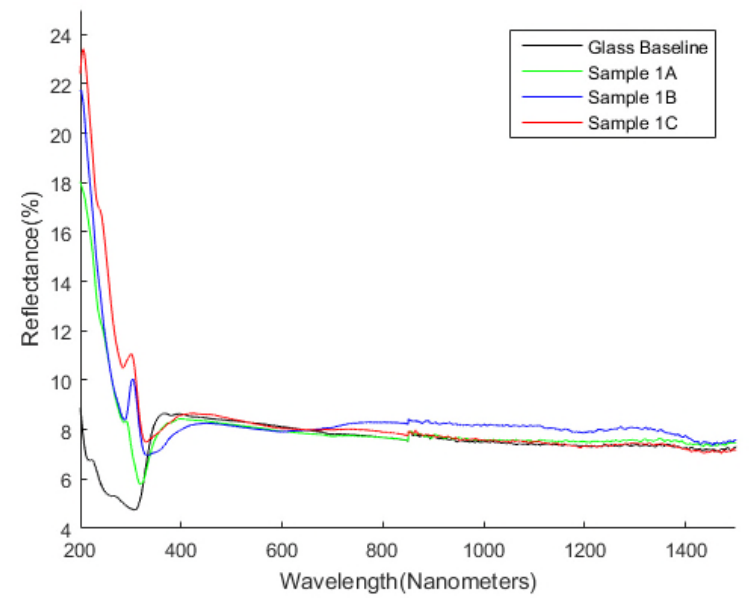

Figure 18 Reflection characteristics of Samples 1A, 1B and 1C. A plot of the glass slide is also given to establish a baseline

Table 1 Spectral characteristics of samples 1A, 1B and 1C (at $665 \mathrm{~nm}$ )

\begin{tabular}{|l|l|l|l|}
\hline Sample & Transmission & Reflection & Absorption \\
\hline 1A & 85.8 & 7.8 & 6.4 \\
\hline 1B & 16.6 & 8.0 & 75.4 \\
\hline 1C & 21.1 & 8.0 & 70.9 \\
\hline
\end{tabular}

An increase in the reflectance at wavelengths below $350 \mathrm{~nm}$ for samples A, B and C in Figure 18 could be associated with resin's intrinsic properties. To further understand this occurrence, the scattering performance of the various samples of batch $\mathrm{C}$ is compared with a resin sample-1A in the wavelength range of $200-350 \mathrm{~nm}$ as shown in Figure 19. It is observed that 
the aerogel composite samples, $1 \mathrm{C}$ and $1.5 \mathrm{C}$, show a sharper and a more distinctive peak as compared to the pure resin sample. Since the film thickness is not monitored precisely, the nature of plots cannot be quantitatively explained in this study. However, the presence of sharper peaks can be qualitatively described as arising from the presence of aerogel particulates in the samples since a similar peak below $250 \mathrm{~nm}$ is also seen in the work of Fernandes et al. (29) for the aerogel samples. Therefore, it is suggested that the sharper peaks of the composite samples in the present study indicate the existence of aerogel within the material at the end of the curing cycle. However, it is also seen that sample $0.5 \mathrm{C}$ does not show the same level of prominence and its value ( $8 \%)$ is similar to glass. This could be due to low viscosity of the resin at the early stage of curing which would have resulted in its greater flow over the glass. The thinner layer of the sample would have caused the instrument to pick up the properties of the glass rather than the sample during the measurement.

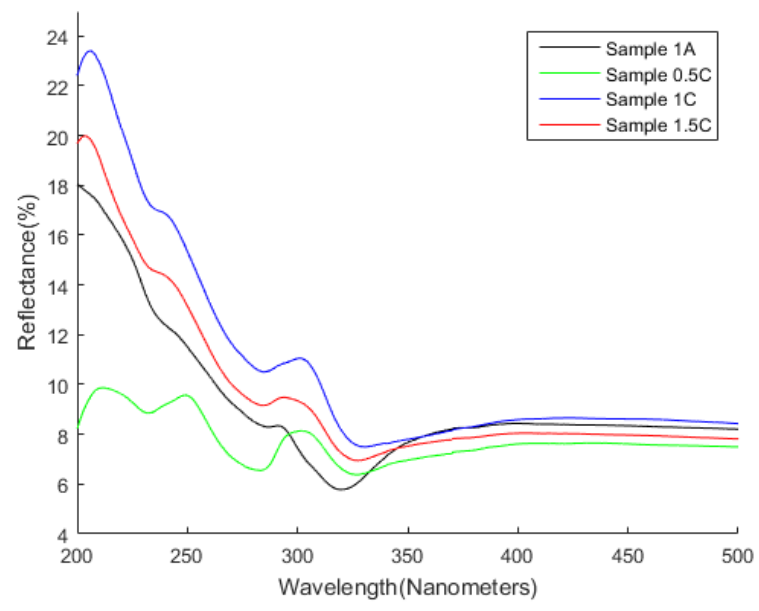

Figure 19 Reflection characteristics of Samples 0.5A, 0.5C, 1C and 1.5C

The analysis of the curing curves in Figure 15 and Figure 16 indicates two possible reasons for the difference in the results of each run for a particular sample. One explanation could be the downward flow of the resin during the measurements which would result in an increased transmission value due to the reduction of the resin thickness as time (and hence, the run number) progresses. This effect is seen in the samples of batch A, where an increase in the transmittance is seen with the number of runs with run 1 showing the lowest transmittance values for each sample. Additionally, the spacing between the graphs at higher run counts is less than at lower run counts; this provides further evidence for the downward flow of the resin because most of the liquid flow occurs initially and as time progress the film becomes more stable and hence less movement resulting in a smaller distance between the graphs of each run. The difference in the graphs of the composite materials could be explained by the change in the density of aerogel due to the infiltration of the resin, which in turn would affect its refractive index (26) and hence the transmittance. Although, there is still a downward motion of the resin in these composites, it is thought the increased viscosity of these samples would limit this movement. In fact, the resin infiltration into the aerogel particle has a greater effect on the transmission properties because of the reduction in the transmission, as opposed to the increased values (seen in batch A) with each run. However, if the flow of the resin during the experiment could be assumed to be mainly due to its viscosity which, would be valid in the present case due to the restriction of the resin to an almost $1 \mathrm{D}$ flow, it could be 
assumed that the rate of infiltration is proportional to the rate of flow into the periphery of the aerogel and hence any change in the graph is due to the flow of the resin.

The results for the samples at 1 hour (Figure 15) and 1.5 hours (Figure 16) show some variations when comparing similar batches across the two times. The results at 1 hour for the composites show a difference in the transmittance between the runs especially the first 3 runs after which, the material starts to stabilise. The difference could be primarily influenced by the resin infiltration into the aerogel particle which in turn is affected by the resin flow hence; most of the change happens initially corroborating the earlier results of batch A. This also implies that the resin is still able to flow easily at this stage of the cure and the lower viscosity would enable the formation of more complex shapes and less force to stir the aerogel particles in. The results for the composite batches at 1.5 hours show almost identical values of transmission for each run. This is thought to be due to the limited resin flow which would reduce the infiltration as well as the mouldability of the sample. Therefore, it is believed that for both batches of aerogel-epoxy composites at 1.5 hours, the viscosity would be high for moulding in commercial applications and as stated previously, could result in an increased force during mixing that may destroy the aerogel. The batches $\mathrm{B}$ and $\mathrm{C}$ show similar results with a slightly increased flow in batch $\mathrm{C}$ due to the presence of the wetting agent which would contribute to a decrease in viscosity of the resin. Nevertheless, this difference is small enough to be neglected and the use of a wetting agent in the manufacturing process is recommended.

\subsection{Thermal Conductivity}

As observed from initial analysis, addition of the aerogel particles at the 1 hour mark show the most promising trend and the incorporation of the wetting agent had little/no effect on the results. Therefore, the thermal conductivity for samples $1 \mathrm{C}$ along with the pure resin (sample 1P) are presented in Table 2. 2 plates of $1 \mathrm{C}(1 \mathrm{C}$ and $1 \mathrm{Cb})$ along with a plate of $1 \mathrm{P}$ were cut to a size of $30 * 30 * 4(\mathrm{~mm})$ from a plaque of the material for the measurements. The results presented are the average of 10 measurements per plate along with the minimum and the maximum value for each sample

Table 2 Thermal conductivity values

\begin{tabular}{|l|l|l|l|}
\hline \multirow{2}{*}{ Sample } & \multicolumn{3}{|c|}{$\begin{array}{c}\text { Thermal Conductivity } \\
(\mathbf{W} /(\mathbf{m} * \mathbf{K}))\end{array}$} \\
\cline { 2 - 4 } & Average & Maximum & Minimum \\
\hline $1 \mathrm{P}$ & 0.2309 & 0.2324 & 0.2282 \\
\hline $1 \mathrm{C}$ & 0.2002 & 0.2010 & 0.1987 \\
\hline $1 \mathrm{Cb}$ & 0.2001 & 0.2112 & 0.1969 \\
\hline
\end{tabular}

The thermal conductivity results gives the pure resin an average value of $0.2309 \mathrm{~W} /(\mathrm{m} * \mathrm{~K})$ and sample $1 \mathrm{C}$ an average value of $0.20015 \mathrm{~W} /(\mathrm{m} * \mathrm{~K})$. This decrease of $13.3 \%$ is thought to be due to the existence of the aerogel particles whose presence has been confirmed by optical and electron microscopy.

\subsubsection{Damage coefficient}

To try and quantify the amount of damage to the aerogel structure, the damage coefficient as originally described in (30) and given in Equation 1 was calculated. 


$$
D_{c}=\frac{\left(k_{s}-k_{l}\right)}{\left(k_{u}-k_{l}\right)}
$$

Equation 1

where $\mathrm{k}_{\mathrm{s}}$ is the thermal conductivity of the sample, $\mathrm{k}_{1}$ is lower thermal conductivity and $\mathrm{k}_{\mathrm{u}}$ is the upper thermal conductivity.

To calculate the values of $k_{1}$ and $k_{u}$, the Hamilton and Crosser model (31) was used to calculate the thermal conductivity of a two component heterogeneous system in which the value of the continuous phase is that of the resin- $0.2309 \mathrm{~W} /\left(\mathrm{m}^{*} \mathrm{~K}\right)$ (sample 1P in Table 2), and the value for the discontinuous phase varied between $0.012 \mathrm{~W} /(\mathrm{m} * \mathrm{~K})(24)$ (thermal conductivity of the aerogel particles) for $\mathrm{k}_{1}$ and $1.4 \mathrm{~W} /(\mathrm{m} * \mathrm{~K})(32)$ (thermal conductivity of pure silica) for $\mathrm{k}_{\mathrm{u}}$. Finally, the volume fraction of the aerogel used was 0.21 which was calculated from the mass fraction (0.03) along with the density of the cured un-reinforced resin $\left(1.19 \mathrm{~g} / \mathrm{cm}^{3}\right)(33)$ and the density of the aerogel $\left(0.135 \mathrm{~g} / \mathrm{cm}^{3}\right)(24)$.

The values of $\mathrm{k}_{1}$ and $\mathrm{k}_{\mathrm{u}}$ were determined as $0.1696 \mathrm{~W} /(\mathrm{m} * \mathrm{~K})$ and $0.3361 \mathrm{~W} /(\mathrm{m} * \mathrm{~K})$ respectively. This data was then substituted into Equation 1 along with the value of $\mathrm{k}_{\mathrm{s}}$, which was 0.20015 for sample 1C (from Table 2). The damage coefficient of the aerogel was then calculated for sample $1 \mathrm{C}$ as 0.183 .

\section{Discussion}

The microscopic images in the present work revealed the presence of the aerogel particles within the epoxy resin matrix. Although, the images do not allow the determination of the internal structure of the aerogel particle, they do permit the observation of the mechanical destruction of the particles seen in samples $1.5 \mathrm{~B}$ and $1.5 \mathrm{C}$. This is an important parameter because the destruction of the aerogel particle would afford a larger surface area for the liquid resin to infiltrate the nano-pores. Therefore, to limit this destruction, the mixing of the aerogel before 1.5 hours of the addition of the resin and hardener is recommended. On the other hand, lower viscosity values of the resin would result in higher infiltration rates; hence the addition of the aerogel should be as delayed as possible. The microscopic images also showed that this balance can be achieved by adding the aerogel at around the 1 hour mark. The EDX analysis also established similar results supporting the damage and resin infiltration phenomena. The smaller silica (aerogel) particles observed in sample 1.5B provides evidence for the mechanical damage of the aerogel particles. On the hand, EDX scans of carbon (C) across an aerogel particle in sample $0.5 \mathrm{~B}$ showed a very low rate of decrease when compared to sample $1 \mathrm{~B}$ wherein, a decrease in the level of carbon is higher and more noticeable and, a well-like structure in the carbon spectrum is obtained. In fact, the spectral mapping of sample 1B in Figure 10 shows a reduction in the intensity of $\mathrm{C}$ and an increase in the intensity of $\mathrm{Si}$ across all aerogel particles. Another limitation of adding the aerogel at 1.5 hours is the reduction in the mouldability of the material due to the higher viscosity of the resin at this stage of the cure. Nevertheless, the recommended timeframe for aerogel addition is valid for this resin system only. To derive a more universal solution, viscosity measurements of the curing resin system at $0.5,1$ and 1.5 hours should be quantified. When comparing the effect of the wetting agent, the results of batch $\mathrm{C}$ are similar to batch $\mathrm{B}$ with the samples at 1 hour demonstrating the most promise for the retention of the aerogel structure and limiting the resin infiltration. But the presence of a wetting agent is expected to increase the adhesion 
between the aerogel particles and the resin thereby, improving the interface between the same. Hence, the use of a wetting agent i.e., batch $\mathrm{C}$ will be useful for durability of the composite structures.

The spectroscopic analysis at $665 \mathrm{~nm}$ had exhibited absorbance in samples 1B and 1C of approximately $75 \%$ and $70 \%$ respectively as compared to around $6 \%$ in sample $1 \mathrm{~A}$ which is quite significant in understanding influence of particulates in aerogel structure. Furthermore, an increase in reflectance below $350 \mathrm{~nm}$ for the aerogel composites that showed sharper peaks unlike the pure resin samples provide additional evidence for the former's existence and possible retention of nano-pores. When comparing the transmittance results during the cure of the material, it is thought that the resin infiltration into the aerogel particles influences the results more than the flow of the resin through the glass slide. Finally, the transmittance plots of the samples at 1 hour showed a greater variance between the runs measured during the cure as compared to the samples at 1.5 hours establishing a higher degree of flow with a less viscous resin and hence, more mouldability for the former.

Therefore from the various experimental techniques and data, sample $1 \mathrm{C}$ is believed to be the most promising material. Nevertheless, to assess the amount of resin infiltration into the aerogel particles and to quantify the materials performance, the thermal conductivity value was measured and compared with the pure resin sample. The pure resin sample had a thermal conductivity value of $0.2309 \mathrm{~W} /\left(\mathrm{m}^{*} \mathrm{~K}\right)$ and the aerogel/epoxy sample's (1C) value was measured at $0.20015 \mathrm{~W} /(\mathrm{m} * \mathrm{~K})$. Zhao et al. (18) state that the aerogel/epoxy composites in their work showed values between $0.105-0.175 \mathrm{~W} /\left(\mathrm{m}^{*} \mathrm{~K}\right)$. However the thermal conductivity of the resin in their work is much lower- between $0.17-0.18 \mathrm{~W} /\left(\mathrm{m}^{*} \mathrm{~K}\right)$ which would reflect in the lower values as compared to the present study. In the work of Kim et al (21) the thermal conductivity of the 'as-received' aerogel/epoxy composites is close to $0.10 \mathrm{~W} /(\mathrm{m} * \mathrm{~K})$ compared to $\sim 0.27 \mathrm{~W} /(\mathrm{m} * \mathrm{~K})$ of the epoxy. The greater decrease in their study could be explained by their choice of resin which is much more viscous than the one used in the present study hence, decreasing the resin infiltration into the aerogel. However as previously discussed, a more viscous resin would result in lower mouldability. Nevertheless, the $13.3 \%$ decrease in thermal conductivity observed in the present work shows the potential in developing aerogel-epoxy composites using the method identified in the present study. To further quantify the amount of resin infiltration, a damage coefficient of 0.183 for sample $1 \mathrm{C}$ was calculated using the method outlined in (30); this could be roughly translated to $18.3 \%$ of the aerogel being damaged. Although, this method is by no means perfect, it does allow a quantification of the damage to the aerogel structure and hence, a means of comparison.

The trend seen in the current paper does show a possibility of using the given processing route in commercial building applications and potentially as a thermal insulation coating on other substrates. It is also believed that a greater decrease in thermal conductivity can be achieved with higher volume fractions of aerogel; however additional experimental data is needed to confirm this theory.

\section{Conclusion}

The current study investigated the possibility of processing aerogel-epoxy composites by incorporating the aerogel at different stages of the curing process. The effect of a wetting agent and its possibility of application were also assessed for enhancing thermal insulation 
capabilities. From microscopic and EDX analysis, the addition of the aerogel particles at 1 hour was seen as the most promising route for the resin system used in terms of limiting the damage to aerogel particles and the resin infiltration into the same but at the same time, maximising the material's mouldability. This was further established by the evaluation of optical transmittance and reflectance. The spectral characteristics also showed an increased absorption in the aerogel-epoxy composites when compared to the pure resin samples. The experimental results also demonstrated a negligible effect of the wetting agent in terms of the retention of aerogel particles hence, advocating its usage. Finally, the thermal conductivity of the aerogel-wetting agent-epoxy system with the aerogel added at 1 hour was determined showing a $13.3 \%$ decrease in the thermal conductivity when compared with the pure resin. This translated to a damage coefficient value of 0.183 thereby, providing support for the described processing route's potential in commercial thermal insulation applications.

\section{Acknowledgements}

The authors would like to thank Mr Jim Hurley, Mr Steve Pope, and Dr Christine Kimpton at Cranfield University along with Mr Thomas Buss at the University of Nottingham for assistance during the material preparation, characterisation and testing. The full resolution microscopic images supporting this article are available at:

https://figshare.com/s/43bba13e75d35f2e765a

The authors would also like to state that no conflict of interest existed during the course of this study.

\section{References}

1. Jin L, Li P, Zhou H, Zhang W, Zhou G, Wang C. Improving thermal insulation of TC4 using YSZ-based coating and $\mathrm{SiO} 2$ aerogel. Prog Nat Sci Mater Int [Internet]. 2015 Apr [cited 2016 Jan 29];25(2):141-6. Available from: http://linkinghub.elsevier.com/retrieve/pii/S1002007115000374

2. Xie T, He Y-L, Tong Z-X, Yan W-X, Xie X-Q. Transient heat transfer characteristic of silica aerogel insulating material considering its endothermic reaction. Int J Heat Mass Transf [Internet]. 2014 Jan [cited 2016 Oct 17];68:633-40. Available from: http://linkinghub.elsevier.com/retrieve/pii/S001793101300848X

3. Kistler SS. Coherent Expanded Aerogels and Jellies. Nature. 1931;127(3211):741.

4. Koravos J, Norwood C, Pescatore P, Pidhurney J. Aerogel Insulative Coatings: New Coating Technology Offers Personnel Protection [Internet]. Paint and Coatings Industry. 2013 [cited 2016 Feb 12]. Available from:

http://www.pcimag.com/articles/98016-aerogel-insulative-coatings

5. Soleimani Dorcheh A, Abbasi MH. Silica aerogel; synthesis, properties and characterization. J Mater Process Technol [Internet]. 2008 Apr [cited 2016 Dec 1];199(1-3):10-26. Available from: http://www.sciencedirect.com/science/article/pii/S0924013607009909

6. Kim GS, Hyun SH. Effect of mixing on thermal and mechanical properties of aerogelPVB composites. J Mater Sci [Internet]. 2003 [cited 2016 Jun 25];38(9):1961-1966. Available from: http://link.springer.com/article/10.1023/A:1023560601911

7. Mazlan N, Khoon TC. ASSESSMENT ON THE COMPRESSIVE STRENGTH 
BEHAVIOR OF HYBRID FILLED EPOXY NANOCOMPOSITE. J Teknol [Internet]. 2015 [cited 2016 Aug 1];76(10). Available from: http://www.jurnalteknologi.utm.my/index.php/jurnalteknologi/article/view/5801

8. Hrubesh LW. Aerogel applications. J Non Cryst Solids. 1998;225:335-42.

9. Baetens R, Petter Jelle B, Gustavsen A. Aerogel insulation for building applications: A state-of-the-art review. Energy Build [Internet]. 2011 [cited 2017 Apr 17];43(4):761-9. Available from: http://ac.els-cdn.com/S0378778810004329/1-s2.0S0378778810004329-main.pdf? tid $=558601 \mathrm{e} 4-2378-11 \mathrm{e} 7-\mathrm{bfc} 1-$ 00000aacb35d\&acdnat $=1492438719$ a846a178c5f9d91692b3bcca5b5f2cb5

10. Ibrahim M, Biwole PH, Wurtz E, Achard P. A study on the thermal performance of exterior walls covered with a recently patented silica-aerogel-based insulating coating. Build Environ [Internet]. 2014 Nov [cited 2016 Mar 7];81:112-22. Available from: http://linkinghub.elsevier.com/retrieve/pii/S0360132314002091

11. Meador MAB, Fabrizio EF, Ilhan F, Dass A, Zhang G, Vassilaras P, et al. Crosslinking Amine-Modified Silica Aerogels with Epoxies: Mechanically Strong Lightweight Porous Materials. Chem Mater [Internet]. 2005 Mar [cited 2016 Mar 7];17(5):1085-98. Available from: http://pubs.acs.org/doi/abs/10.1021/cm048063u

12. Wei T-Y, Lu S-Y, Chang Y-C. Transparent, Hydrophobic Composite Aerogels with High Mechanical Strength and Low High-Temperature Thermal Conductivities. J Phys Chem B [Internet]. 2008 Sep [cited 2016 Jan 27];112(38):11881-6. Available from: http://pubs.acs.org/doi/abs/10.1021/jp804855v

13. Schmidt M, Schwertfeger F. Applications for silica aerogel products. J Non Cryst Solids [Internet]. 1998 [cited 2016 Jun 25];225:364-368. Available from: http://www.sciencedirect.com/science/article/pii/S0022309398000544

14. Ivankovic M, Brnardic I, Ivankovic H, Mencer HJ. DSC study of the cure kinetics during nanocomposite formation: Epoxy/poly(oxypropylene) diamine/organically modified montmorillonite system. J Appl Polym Sci. 2006;99:550-7.

15. Hayaty M, Beheshty MH, Esfandeh M. Isothermal differential scanning calorimetry study of a glass/epoxy prepreg. Polym Adv Technol [Internet]. 2011 [cited 2017 May 21];22(6):1001-6. Available from:

http://onlinelibrary.wiley.com/store/10.1002/pat.1607/asset/1607_ftp.pdf;jsessionid=D 2BE592E70C767A650ACD73393035C0E.f03t01? $\mathrm{v}=1 \& \mathrm{t}=\mathrm{j} 2 \mathrm{yy} 6 \mathrm{uxi} \& \mathrm{~s}=762 \mathrm{f02114f8e}$ 8309a4fd9d09a1c91f945e99005d

16. Poisson N, Lachenal G, Sautereau H. Near-and mid-infrared spectroscopy studies of an epoxy reactive system. Vib Spectrosc [Internet]. 1996 [cited 2017 Jun 5];12:237-47. Available from: http://ac.els-cdn.com/0924203196000276/1-s2.0-0924203196000276main.pdf?_tid=fcd1e2be-49df-11e7-90f200000aacb361\&acdnat $=1496661382 \_763 a 98$ ae24bd25a82553e4bdcaa4d667

17. Basri MSM, Mazlan N, Mustapha F. Effects of stirring speed and time on water absorption performance of silica aerogel/epoxy nanocomposite. ARPN J Eng Appl Sci [Internet]. 2015 [cited 2016 Aug 1];10(21):9982-91. Available from: http://www.arpnjournals.org/jeas/research_papers/rp_2015/jeas_1115_3016.pdf

18. Zhao JP, Ge DT, Zhang SL, Wei XL. Studies on Thermal Property of Silica Aerogel/Epoxy Composite. Mater Sci Forum [Internet]. 2007 [cited 2017 Nov 
30];546-549:1581-4. Available from:

http://citeseerx.ist.psu.edu/viewdoc/download?doi=10.1.1.981.417\&rep=rep1\&type=p df

19. Gupta N, Ricci W. Processing and compressive properties of aerogel/epoxy composites. J Mater Process Technol [Internet]. 2008 Mar [cited 2016 Mar 11];198(13):178-82. Available from: http://linkinghub.elsevier.com/retrieve/pii/S0924013607006668

20. Vahtrus M, Oras S, Antsov M, Reedo V, Mäeorg U, Lõhmus A, et al. Mechanical and thermal properties of epoxy composite thermal insulators filled with silica aerogel and hollow glass microspheres. Proc Est Acad Sci [Internet]. 2017 [cited 2017 Nov 30];66(4):339-46. Available from: https://doi.org/10.3176/proc.2017.4.03

21. Kim HM, Kim HS, Kim SY, Youn JR. Silica aerogel/epoxy composites with preserved aerogel pores and low thermal conductivity. e-Polymers [Internet]. 2015 Jan [cited 2016 Jun 21];15(2). Available from:

http://www.degruyter.com/view/j/epoly.2015.15.issue-2/epoly-2014-0165/epoly-20140165.xml

22. Centre for Disease Control and Prevention. ETHANOL (ANHYDROUS) International Chemical Safety Cards - NIOSH [Internet]. National Institute for Occupational Safety and Health (NIOSH). 2014 [cited 2018 Jan 31]. Available from: https://www.cdc.gov/niosh/ipcsneng/neng0044.html

23. United States Department of Labor. Green Job Hazards: Biofuels [Internet]. Occupational Safety \& Health Administration . [cited 2018 Jan 31]. Available from: https://www.osha.gov/dep/greenjobs/biofuels.html

24. BuyAerogel.com | Enova ${ }^{\circledR}$ Aerogel IC3110 Particles [Internet]. [cited 2016 Aug 8]. Available from: http://www.buyaerogel.com/product/enova-aerogel-ic3110/

25. Hexion Inc. EPIKOTE Resin MGS RIMR 135 and EPIKURE Curing Agent MGS RIMH 134-RIMH 137 [Internet]. Technical Data Sheet. 2006 [cited 2018 Jan 20]. Available from: http://www.metyx.com/wpcontent/uploads/PDF_Files/Hexion/TDS/TDS RIMH 137.pdf

26. Buzykaev AR, Danilyuk AF, Ganzhur SF, Kravchenko EA, Onuchin AP. Measurement of optical parameters of aerogel. Nucl Instruments Methods Phys Res Sect A Accel Spectrometers, Detect Assoc Equip [Internet]. 1999 Aug 21 [cited 2017 Oct 29];433(1-2):396-400. Available from: https://www.sciencedirect.com/science/article/pii/S0168900299003253

27. Bhattacharyya D, Targa M, Nicholls JR. Electron beam physical vapour deposited zirconia based ceramics for developments of solar surface coatings. Surf Eng [Internet]. 2012 Mar 12 [cited 2018 Feb 5];28(2):122-8. Available from: http://www.tandfonline.com/doi/full/10.1179/1743294411Y.0000000070

28. Epoxy Technology. Understanding Optical Properties for Epoxy Applications [Internet]. Tech Tip 18. 2012 [cited 2018 Jan 10]. Available from: http://www.epotek.com/site/files/Techtips/pdfs/tip18.pdf

29. Fernandes CD, Bridges JC, Grady MM. UV AND VISIBLE WAVELENGTH REFLECTANCE SPECTROSCOPY OF AEROGEL AND OF STARDUST GRAINS. Lunar Planet Sci [Internet]. 2007 [cited 2018 Jan 20];XXXVIII. Available 
from:

http://oro.open.ac.uk/8131/1/UV_and_Visible_Wavelength_Reflectance_Spectroscopy _of_Aerogel_and_of_Stardust_Grains.pdf

30. Krishnaswamy S, Tinsley L, Marchante V, Addepalli S, Huang Z, Abhyankar H. Effect of extrusion and compression moulding on the thermal properties of nylon6/silica aerogel composites. J Thermoplast Compos Mater [Internet]. 2017 [cited 2017 Nov 29];89270571772919. Available from:

http://journals.sagepub.com/doi/pdf/10.1177/0892705717729198

31. Hamilton RL, Crosser OK. Thermal conductivity of heterogeneous two-component systems. Ind Eng Chem Fundam [Internet]. 1962 [cited 2016 Mar 30];1(3):187-191. Available from: http://pubs.acs.org/doi/abs/10.1021/i160003a005

32. Silica-Silicon Dioxide (SiO2) properties [Internet]. [cited $2016 \mathrm{Sep} 29$ ]. Available from: http://www.azom.com/properties.aspx?ArticleID=1114

33. PRF Composites. Ultra Low Viscosity Epoxy Resin System RS-M135 [Internet]. Product Data Sheet. 2013 [cited 2017 Oct 13]. Available from:

http://www.prfcomposites.com/store/image/data/PDF/RS-M135.pdf 
2018-08-15

\title{
Morphological, optical and thermal characterisation of aerogel-epoxy composites for enhanced thermal insulation
}

\author{
Krishnaswamy, Suryanarayanan
}

SAGE

Suryanarayanan Krishnaswamy, Debabrata Bhattacharyya, Hrushikesh Abhyankar, et al., Morphological, optical and thermal characterisation of aerogel-epoxy composites for enhanced thermal insulation. Journal of Composite Materials, Volume 53, Issue 4, March 2019, pp. 909-923 https://doi.org/10.1177/0021998318793194

Downloaded from Cranfield Library Services E-Repository 